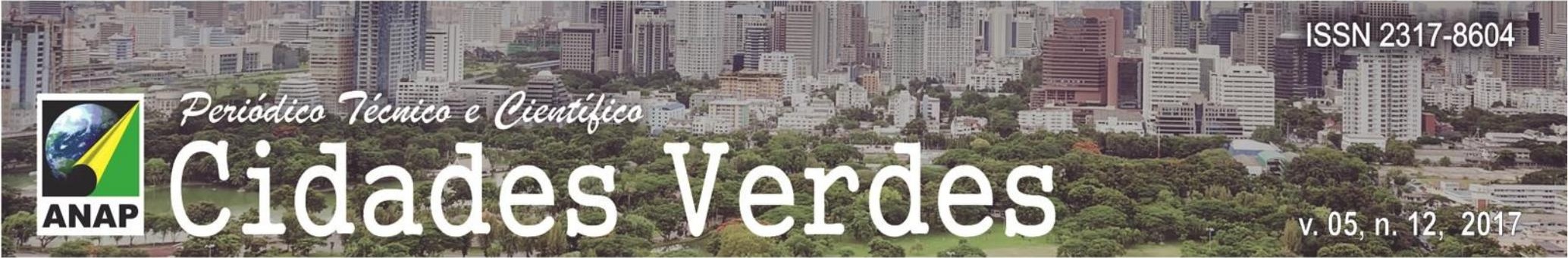

\title{
Gestão dos resíduos sólidos urbanos no município de Presidente Prudente /SP
}

Management of solid urban waste in the municipality of Prudent President / SP

Gestión de los residuos sólidos urbanos en el municipio de Presidente Prudente / SP

\author{
Alessandra Harumi Sakai dos Santos \\ Mestranda em Meio Ambiente e Desenvolvimento Regional, Unoeste. \\ Alessandra.sakai@hotmail.com \\ Juliene Maldonado Orosco de Andrade \\ Mestranda em Meio Ambiente e Desenvolvimento Regional, Unoeste. \\ julieneorosco@hotmail.com \\ Edilene Mayumi Murashita Takenaka \\ Docente do Mestrado em meio Ambiente e Desenvolvimento Regional, Unoeste. \\ edilene@unoeste.br
}




\section{RESUMO}

A questão ambiental vem sendo tratada com grande importância. Alicerçadas a preocupação com a sustentabilidade e a responsabilidade socioambiental. Aspectos a considerar no confronto envolvem, além de questões ambientais, questões técnicas complexas, econômicas, de produção e consumo sustentáveis, de educação e cidadania, e sociais. O consumo aumentou consideravelmente em função do crescimento populacional e vem cada vez mais tendendo a grandes proporções, onde as industrias precisam produzir cada vez para atender essa crescente demanda, o que resulta em um maior montante de resíduos gerados, requerendo a adoção de práticas corretas ligadas a uma gestão devidamente adequada para esses resíduos gerados. A gestão dos resíduos sólidos possui atitude ativa e demanda táticas, que inclui toda a sociedade e supere o panorama ambiental. O complexo associado à gestão de resíduos sólidos deve-se às implicações ativas do poder público, ação privada e coletividade civil. 0 município de Presidente Prudente apresenta índices inadequados a disposição de resíduos sólidos urbanos. A pesquisa irá analisar as estratégias praticadas no munício de Presidente Prudente, e finalizará na conclusão a sugestão de práticas para desenvolvimento sustentável, alicerçados nas políticas públicas ambientais.

PALAVRAS-CHAVE: Gestão. Resíduos sólidos. Políticas públicas.

\section{SUMMARY}

The environmental issue has been treated with great importance. Based on the concern for sustainability and socioenvironmental responsibility. Aspects to be considered in the confrontation involve, in addition to environmental issues, complex technical, economic, production and consumption, education and citizenship, and social issues. Consumption has increased considerably as a result of population growth and is increasingly tending to large proportions, where industries need to produce each time to meet this growing demand, resulting in a larger amount of waste generated, requiring the adoption of correct practices linked properly managed for such waste generated. The management of solid waste has an active attitude and demand tactics, which includes the entire society and surpasses the environmental panorama. The complex associated to the management of solid waste is due to the active implications of the public power, private action and civil collectivity. The municipality of Presidente Prudente has inadequate indices for the disposal of municipal solid waste. The research will analyze the strategies practiced in the Presidente Prudente ammunition, and will finalize the suggestion of practices for sustainable development, based on public environmental policies.

KEYWORDS: Management. Solid waste. Public policy.

\section{RESUMEN}

La cuestión ambiental viene siendo tratada con gran importancia. Basadas en la preocupación por la sostenibilidad y la responsabilidad socioambiental. Los aspectos a considerar en la confrontación involucra, además de cuestiones ambientales, cuestiones técnicas complejas, económicas, de producción y consumo sostenibles, de educación y ciudadanía, y sociales. El consumo aumentó considerablemente en función del crecimiento poblacional y cada vez tiende a grandes proporciones, donde las industrias necesitan producir cada vez para atender esa creciente demanda, lo que resulta en un mayor monto de residuos generados, requiriendo la adopción de prácticas correctas ligadas a una gestión debidamente adecuada para esos residuos generados. La gestión de los residuos sólidos tiene actitud activa y demanda tácticas, que incluye a toda la sociedad y supera el panorama ambiental. El complejo asociado a la gestión de residuos sólidos se debe a las implicaciones activas del poder público, la acción privada y la colectividad civil. El municipio de Presidente Prudente presenta índices inadecuados a disposición de residuos sólidos urbanos. La investigación analizará las estrategias practicadas en el municio de Presidente Prudente, y finalizará en la conclusión la sugerencia de prácticas para el desarrollo sostenible, basadas en las políticas públicas ambientales. 


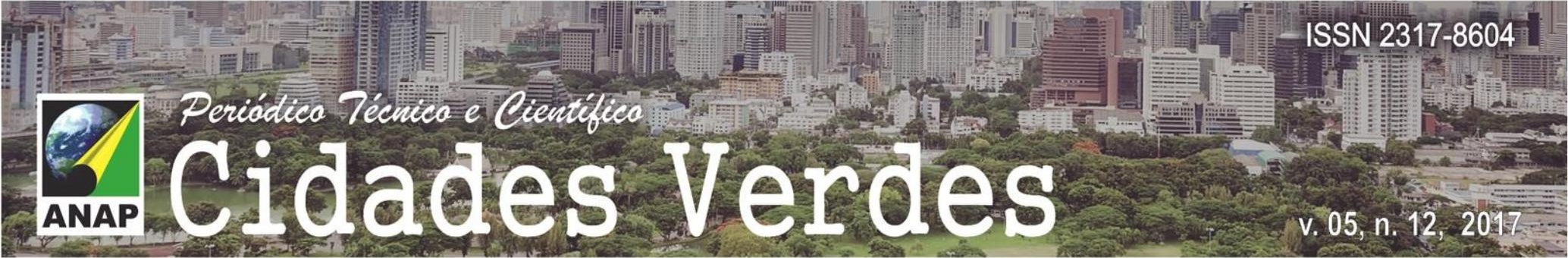

PALABRAS CLAVE: Gestión. Residuos sólidos. Políticas públicas. 


\section{INTRODUÇÃO}

Hodiernamente a questão ambiental vem sendo tratada com grande importância. Existe uma grande preocupação com a sustentabilidade e a responsabilidade socioambiental, que deve ser vista de forma conjunta em todos os seus aspectos. Os aspectos a considerar neste enfrentamento envolvem, além de questões ambientais, questões técnicas complexas, econômicas, de produção e consumo sustentáveis, de educação e cidadania, e sociais.

Com o crescimento populacional, o consumo vem cada vez mais tendendo a grandes proporções, onde as industrias precisam produzir cada vez para atender essa crescente demanda, o que resulta em um maior montante de resíduos gerados. Isso requer a adoção de práticas corretas atreladas a uma gestão devidamente adequada para esses resíduos gerados.

A gestão dos resíduos sólidos possui atitude ativa e demanda táticas de enfrentamento colaterais, que inclui toda a sociedade e supere o panorama ambiental.

Parte da complexidade associada à gestão de resíduos sólidos deve-se às implicações ativas do poder público, ação privada e coletividade civil, quer como causador ou usufrutuário, quer como prestador de serviços, formulador de regulamentos ou executor de políticas públicas.

Para isso os objetivos desta pesquisa foi estudar a gestão adotada nos lixões/aterro no município de Presidente Prudente/SP, relacionando as Políticas Públicas Estaduais vigentes. Como os objetivos específicos:

- Identificar as políticas públicas relacionadas à disposição de resíduos sólidos urbanos;

- Descrever a atual situação dos lixões/aterro do município;

- Sugerir práticas de gestão/gerenciamento dos lixões e aterros pautados nas políticas públicas estaduais.

O município de Presidente Prudente apresenta índices inadequados a disposição de resíduos sólidos urbanos, o que pode causar grande impacto ambiental e consequentemente afetar o ser humano.

A metodologia utilizada será a pesquisa aplicada bibliográfica, com o levantamento de dados a partir da documentação indireta em fontes primárias e secundárias.

$\mathrm{O}$ artigo organiza-se no conhecimento do que tange as políticas públicas, bem como a normatização estadual. Partindo para as estratégias praticadas no munício de Presidente Prudente, e finalizando na conclusão a sugestão de práticas para desenvolvimento sustentável, alicerçados nas políticas públicas ambientais.

\section{DESENVOLVIMENTO}

\subsection{Estrutura do sistema ambiental Paulista}

O órgão central do sistema ambiental paulista é a Secretaria do Meio Ambiente do Estado de São Paulo - SMA, criada em 1986, surgiu para promover a preservação, melhoria e recuperação da qualidade ambiental, coordenando e integrando atividades ligadas à defesa do meio ambiente. É responsável pela elaboração da Política Estadual de Meio Ambiente, estabelecimento do Sistema Estadual de Administração da Qualidade Ambiental, Proteção, Controle e Desenvolvimento do Meio Ambiente e Uso Adequado dos Recursos Naturais (SEAQUA). Também é responsável por analisar e acompanhar as políticas públicas setoriais 


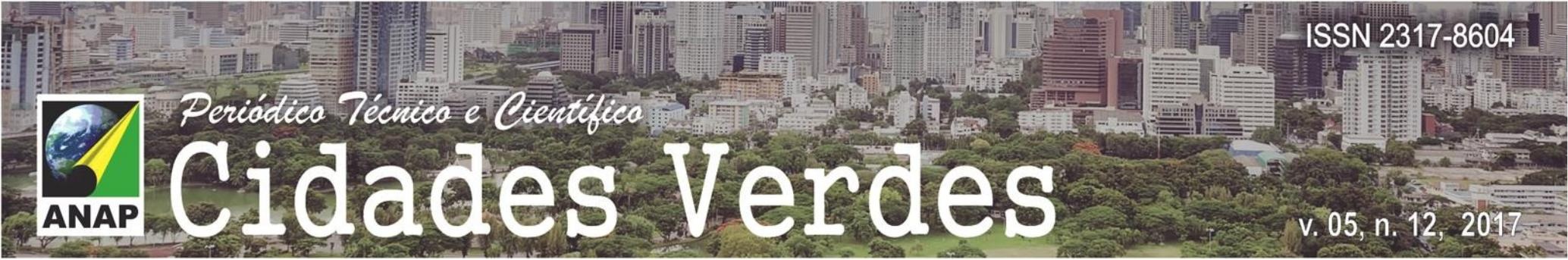

É indispensável que o governo tenha a gestão ambiental também como prioridade. Prudente precisa garantir o aterro sanitário adequado. A cidade ainda o denomina de lixão porque se acostumou desta forma, porém atualmente é como um aterro, controlado. A Lei Nacional de Resíduos Sólidos (Lei 2.305/10) disciplina sobre o assunto, (ADMINISTRAÇÃO...2016).

Diante disso, nota-se que o município de Presidente Prudente necessita de regulamentação em relação ao "Lixão", pois este poderá causar sérios danos ambientais.

Em entrevista feita pela Secretaria Municipal de comunicação, no lixão os trabalhadores estão finalizando o cercamento da área, estando $90 \%$ concluído, onde já foram colocados os tubos de drenagem de gás e está sendo planejado a inserção de grama, Milton Carlos de Mello, prefeito de Presidente Prudente verifica o encerramento do lixão, (SEDEPP, 2016), conforme figura 1.

Figura 1: Área do Lixão do município de Presidente Prudente

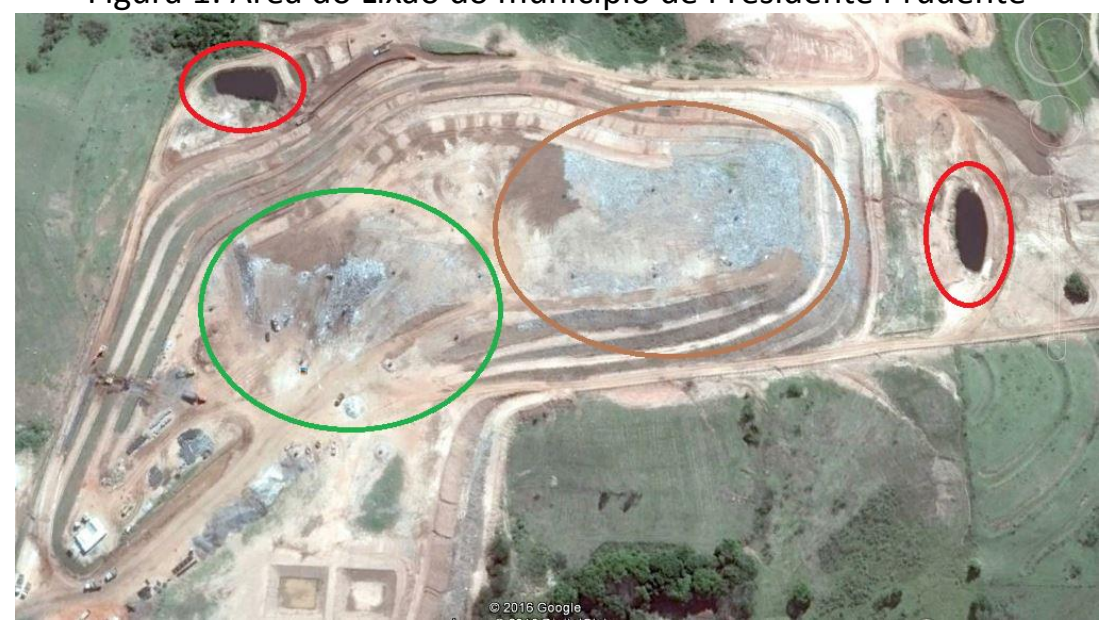

Fonte: Earth Explorer, 2016.

Elaborado pelas autoras

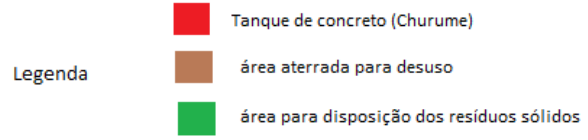

Conforme Ramos (2014) os lixos ao serem lançados no solo, por mais que sejam não perigosos podem causar sérios danos ambientais, pois estes através dos fenômenos da natureza podem ser levados para outros lugares resultando em graves consequências prejudicando assim o lençol freático. Assim o autor expõe uma preocupação atrelada à preocupação ambiental.

A Cetesb (2016), afirmou que foi delimitado uma área para disposição dos resíduos sólidos (área em marrom, figura 1) até regularizarem uma área específica para a inserção do aterro sanitário. Ainda salienta a importância dos aterros sanitários, pois pode proteger a terra, a atmosfera e os recursos hídricos.

A área no Distrito Industrial do município de Presidente Prudente, para disposição dos resíduos sólidos urbanos está em processo de desativação e precisa atender ao Termo de 
ajuste e conduta assinado pela prefeitura municipal, o qual necessitará de uma nova área para implantar o novo aterro sanitário municipal, (TAKENAKA, 2008).

Conforme a autora, desde 2008 existe há preocupação com encerramento do "lixão" até os dias atuais. 0 ministério Público há 8 anos vem exigindo a regularização da situação do lixão no município de Presidente Prudente. Atualmente já se discute para decidir a área que será instalada o aterro sanitário no município.

\subsection{Políticas Governamentais referentes a resíduos sólidos}

A complexidade do tema resíduos sólidos mostrou-se evidente no processo de formulação da Política Nacional de Resíduos Sólidos (PNRS), instituída pela Lei Federal no 12.305, de 2 de agosto de 2010, após 21 anos de tramitação. A PNRS, traz como princípios prevenção e precaução, classifica os resíduos sólidos quanto à origem e à periculosidade, e faz distinção entre resíduo ${ }^{1}$ e rejeito ${ }^{2}$. De forma a assegurar a governança do processo de implantação da PNRS, cria o Comitê Interministerial e o Comitê Orientador para a Implantação dos Sistemas de Logística Reversa. Dentre as metas da PNRS foram a elaboração dos planos de resíduos sólidos até agosto de 2012 e a disposição final ambientalmente adequada dos rejeitos até agosto de 2014.

A Política Estadual de Resíduos Sólidos de São Paulo (PERS), instituída pela Lei Estadual no 12.300 , de 16 de março de 2006, e regulamentada pelo Decreto Estadual no 54.645, de 5 de agosto de 2009, a partir de um processo que se iniciou em 1998. A PERS categoriza os resíduos sólidos conforme a origem e define gestão integrada e compartilhada, sendo uma política de proteção à saúde pública e aos ecossistemas, de inclusão social e desenvolvimento. Ainda, inova com princípios como a promoção de padrões sustentáveis de produção e consumo, a prevenção da poluição por redução na fonte, a adoção dos princípios do poluidorpagador e da responsabilidade pós-consumo.

Considerando os princípios da gestão integrada e compartilhada, ficaram estabelecidos pela PERS como responsáveis pela gestão de resíduos sólidos:

- todos os geradores, equiparando-se ao gerador o órgão municipal ou a entidade responsável pela coleta, pelo tratamento e pela disposição final dos resíduos urbanos;

- os geradores de resíduos industriais, sendo responsáveis pelo gerenciamento desde a geração até a disposição final;

- os produtores ou importadores de matérias primas, de produtos intermediários ou acabados, transportadores, distribuidores, comerciantes, consumidores, catadores, coletores, administradores e proprietários de área de uso público e coletivo e operadores de resíduos sólidos em qualquer das fases do gerenciamento dos resíduos sólidos; o gerador, no caso do emprego de resíduos industriais perigosos, mesmo que tratados, reciclados ou recuperados para utilização como adubo, matéria prima ou fonte de energia, bem como no caso de suas incorporações em materiais, substâncias ou produtos (o que dependerá de prévia aprovação dos órgãos competentes);

- no caso de ocorrências envolvendo resíduos que coloquem em risco o ambiente e a saúde pública, o gerador, nos eventos ocorridos em suas instalações; o gerador e o transportador, nos eventos ocorridos durante o transporte de resíduos sólidos; o gerador e o gerenciador de unidades receptoras, nos eventos ocorridos nas instalações destas últimas. (BRASIL, 2006)

\footnotetext{
${ }^{1}$ Material que pode ser reaproveitado ou reciclado

${ }^{2} \mathrm{O}$ que não é passível de reaproveitamento ou reciclagem
} 
Reafirmando as responsabilidades trazidas pela PERS, a PNRS incumbe ao Distrito Federal e aos Municípios a gestão integrada dos resíduos sólidos gerados nos respectivos territórios, sem prejuízo das competências de controle e fiscalização dos órgãos federais e estaduais do Sistema Nacional do Meio Ambiente (SISNAMA), Sistema Nacional de Vigilância Sanitária (SNVS) e Sistema Unificado de Atenção à Sanidade Agropecuária (SUASA), bem como da responsabilidade do gerador pelo gerenciamento de resíduos. Ainda, especifica que o gerador de resíduos sólidos domiciliares tem cessada sua responsabilidade pelos resíduos com a disponibilização adequada para a coleta ou, com a devolução dos resíduos em que se aplica a logística reversa. Por fim, estabelece que, se o titular do serviço público de limpeza urbana e de manejo de resíduos sólidos, por acordo setorial ou termo de compromisso firmado com o setor empresarial, encarregar-se de atividades de responsabilidade dos fabricantes, importadores, distribuidores e comerciantes nos sistemas de logística reversa dos produtos e embalagens, as ações do poder público serão devidamente remuneradas, na forma previamente acordada entre as partes.

Como instrumento da PNRS e da PERS, o Plano Estadual de Resíduos Sólidos, deve estar em consonância com os objetivos e as diretrizes das políticas citadas e do Plano Plurianual Estadual vigente seguindo as diretrizes orçamentárias e orçamento anual (BRASIL, 2011) estando em consonância com os planos de saneamento básico municipais, a legislação ambiental e regulamentos na área de saúde, educação ambiental e transporte, dentre outros.

\subsection{Ações e Programas do Sistema Ambiental em vigência}

Para fins de aprimoramento dos mecanismos de gestão ambiental e em cumprimento a dispositivos legais, a CETESB iniciou em 1997 a organização e sistematização anual de informações e dados sobre geração e condições ambientais e sanitárias dos locais de tratamento e disposição final de resíduos sólidos domiciliares dos municípios paulistas.

Ao longo de 16 anos de publicação, a CETESB aperfeiçoou tecnicamente os critérios de pontuação e classificação dos locais de destinação, com base no conhecimento e experiência adquiridos, tornando os procedimentos alinhados aos preconizados na PNRS e PERS. Os dados inventariados expressam as condições ambientais dos locais de tratamento e disposição de resíduos sólidos domiciliares por meio dos índices de Qualidade de Aterro de Resíduos (IQR), de Qualidade de Aterro de Resíduos em Valas (IQR-Valas) e de Qualidade de Usinas de Compostagem (IQC), (CETESB, 2015). Os índices são estratificados em duas categorias ${ }^{3}$.

Para todos os municípios que apresentavam irregularidades na destinação final de resíduos sólidos, foi proposta a assinatura de um Termo de Compromisso de Ajustamento de Conduta - TAC. Nele foi consignado os compromissos das administrações municipais, visando à regularização ou ao encerramento de aterros irregulares e à adoção de uma solução técnica definitiva e regularmente implantada. Em todos os casos, as ações desenvolvidas devem possibilitar a adequação técnica e ambiental das instalações, seguidas de seu correspondente licenciamento ambiental, bem como, a remediação de passivos ambientais existentes. Atualmente, para casos pontuais, a CETESB ainda tem firmado novos TACs com as mesmas finalidades, inclusive com a participação do Ministério Público.

Em prosseguimento às atividades desenvolvidas e reafirmando as responsabilidades trazidas pelo PERS e PNRS, ainda, em consonância com o estabelecido no Programa Otimização da Gestão Municipal de Resíduos Sólidos no Estado de São Paulo, das Diretrizes 2015-2018 da SMA, foi constituído, em junho de 2015, um grupo de trabalho, com técnicos das Diretorias de Controle e Licenciamento Ambiental, de Avaliação de Impacto Ambiental e

\footnotetext{
${ }^{3}$ Adequado e Inadequado (são alvo das ações de controle da CETESB)
} 
de Engenharia e Qualidade Ambiental da CETESB, para apoiar as ações das agências ambientais junto aos municípios que possuíam aterros com IQR em Condição Inadequada $(I Q R<7,1)$. Este grupo vistoriou diversos aterros em 60 municípios e manteve contato com as respectivas Prefeituras, conjuntamente com os técnicos das agências ambientais. A tarefa deste grupo foi de identificar os problemas técnicos desses aterros, indicá-los aos dirigentes municipais e reforçar que a CETESB continua à disposição para orientar quanto à adequação da gestão dos resíduos sólidos para a solução dos problemas constatados, sem prejuízo das ações administrativas pertinentes. O trabalho de orientação desenvolvido pelo grupo de trabalho se ateve às atribuições de competência da CETESB na questão de adequação da disposição dos resíduos sólidos, uma das metas do Plano Estadual de Resíduos Sólidos. Verificou-se ainda a existência de diversos problemas nos municípios visitados que contribuem para a atual realidade observada, tais como: o esgotamento das áreas de disposição dos resíduos urbanos; a indisponibilidade de novas áreas em decorrência das restrições técnicas, locacionais e legais incidentes como, por exemplo, aquelas relativas às áreas especialmente protegidas e à proximidade a aeródromos; as dificuldades na implantação de políticas de redução, reutilização e reciclagem; os altos índices pluviométricos registrados no período, e, ainda, a grande dificuldade financeira enfrentada pelas municipalidades, agravada pela crise econômica e pela diminuição na arrecadação, que repercutem diretamente na disponibilidade de recursos para a operação dos aterros. Em alguns casos nota-se que essa situação é agravada pela inércia do poder público municipal. Na tabela 1, e na figura 2 demonstram a situação atual no município de Presidente Prudente.

Tabela 1: Condições do aterro no município de Presidente Prudente

\begin{tabular}{|c|c|c|c|c|c|c|c|c|c|c|c|c|c|c|c|}
\hline \multirow{3}{*}{\multicolumn{2}{|c|}{ MUNICIPIO }} & \multirow{3}{*}{$\begin{array}{c}\text { AGÊNCIA } \\
\text { AMBIENTAL }\end{array}$} & \multirow{3}{*}{ RSU(tdia) 2} & \multicolumn{7}{|c|}{ INVENTARIO } & \multirow{3}{*}{\multicolumn{2}{|c|}{ ENQUADRAMENTO E OBSERVAÇĀO }} & \multirow{3}{*}{ TAC } & \multirow{3}{*}{ LI } & \multirow{3}{*}{10} \\
\hline & & & & 2011 & & 201 & & 201 & & 2015 & & & & & \\
\hline & & & & IQR & IQR & IQR & & $R \mid$ & & & & & & & \\
\hline ANHUMAS & $+\# \S$ & Pres. Prudente & 2,29 & & 8,5 & 9,2 & & 8,4 & & 8,4 & A & & Năo & Sim & Sim \\
\hline CAIUA & + & Pres. Prudente & 1,49 & 8,5 & 7,3 & 7,3 & & 7,5 & & 7,5 & A & & Năo & Sim & Sim \\
\hline ESTRELA DO NORTE & \% & Pres. Prudente & 1,53 & 7,8 & 7,3 & 7,7 & & 8,7 & & 7.4 & A & & Năo & Năo & Năo \\
\hline EUCLIDES DA CUNHA PAULISTA & + & Pres. Prudente & 4,30 & 6,1 & 7,5 & 7,2 & & 7,1 & & 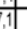 & A & & Năo & Sim & Sim \\
\hline IEPE & * & Pres. Prudente & 4,99 & 7,1 & 7,2 & 7,2 & & 5,1 & & 7.9 & A & & Năo & Sim & Sim \\
\hline MARABA PAULISTA & $\%$ & Pres. Prudente & 1,69 & 8,2 & 7,7 & 7,3 & & 7,1 & & (3.3. & A & & Năo & Sim & Sim \\
\hline MIRANTE DO PARANAPANEMA & 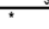 & Pres. Prudente & 7,41 & 6,8 & 6,7 & 8,2 & & 7,3 & & $\frac{1}{72}$ & A & & Năo & Sim & Sim \\
\hline NANTES & + & Pres. Prudente & 1,87 & 7,5 & 7,6 & $\frac{7,2}{7,2}$ & & 9.5 & & $\frac{15}{3.5}$ & $\frac{1}{A}$ & & Năo & Sim & Sim \\
\hline NARANDIBA & * & Pres. Prudente & 2,36 & 7,1 & 8,5 & 8,5 & & 7,2 & & 7.4 & A & & Näo & sim & Sim \\
\hline PIRAPOZINHO & \% & Pres. Prudente & 20,21 & 5 & $\frac{4,2}{4,2}$ & $\frac{7,4}{4,2}$ & & $\frac{15}{28}$ & & 36 & f & & Sim & Sim & Năo \\
\hline PRESIDENTE BERNARDES & + & Pres. Prudente & 7,35 & 7,1 & 7,1 & 7,1 & & 9,0 & & 7,2 & A & & Năo & Sim & Sim \\
\hline PRESIDENTE EPITACIO & + & Pres. Prudente & 32,49 & 5,9 & 2,9 & 7,2 & & 7,4 & & 0,1 & f & & Năo & $\operatorname{sim}$ & Nào \\
\hline PRESIDENTE PRUDENTE & & Pres. Prudente & 195,89 & 3,8 & 2,7 & 2,5 & & 2,7 & & s, & t & & Sim & Năo & Năo \\
\hline PRESIDENTE VENCESLAU & $\%$ & Pres. Prudente & 30,16 & 6.2 & 6,1 & 7,1 & & 8.4 & & 9,4 & $A$ & & Năo & Sim & Sim \\
\hline REGENTE FEIJO & * & Pres. Prudente & 12,73 & 8,0 & 7,6 & 7,6 & & 7,5 & & 7,3 & $A$ & & Năo & Sim & Sim \\
\hline ROSANA & + & Pres. Prudente & 10,41 & 5,9 & 7,3 & 7,6 & & 7,2 & & 7,4 & A & & Năo & Năo & Năo \\
\hline \begin{tabular}{|l} 
SANDOVALINA \\
\end{tabular} & $\cdot$ & Pres. Prudente & 1,99 & $\frac{9.9}{6.9}$ & 6.9 & 7,4 & & 7.5. & & $\frac{4}{72}$ & $\frac{A}{A}$ & & Năo & sim & Sim \\
\hline SANTO ANASTACIO & $\%$ & Pres. Prudente & 13,73 & $\frac{69}{6,9}$ & 8,5 & 7,2 & & 7,1 & & 7.2 & $A$ & & Năo & Sim & Sim \\
\hline TACIBA & 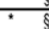 & Pres. Prudente & 3,163 & $\frac{1,2}{7,2}$ & 6,7 & $\frac{7.0}{80}$ & & 85 & & $\frac{1}{71}$ & $\frac{1}{A}$ & & Nẵo & Sim & Sim \\
\hline TARABAl & + & \begin{tabular}{|l|} 
Pres. Prudente \\
\end{tabular} & 4,64 & 7,7 & 8,5 & 8,0 & & 7,4 & & 90 & A & & Năo & Sim & Sim \\
\hline TEODORO SAMPAIO & $\%$ & \begin{tabular}{|l|} 
Pres. Prudente \\
\end{tabular} & 12,89 & 6,2 & 7,2 & 7,9 & & 7,5 & & 7.8 & A & & Năo & sim & Sim \\
\hline
\end{tabular}

Fonte: Inventario Cetesb, 2015.

Figura 2: Mapeamento sobre condições dos Aterros no Pontal do Paranapanema 

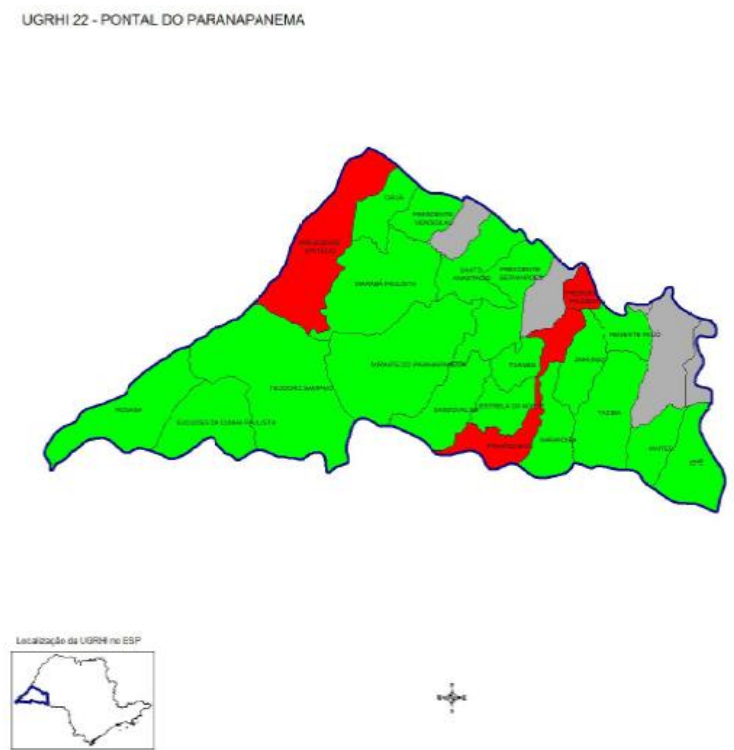
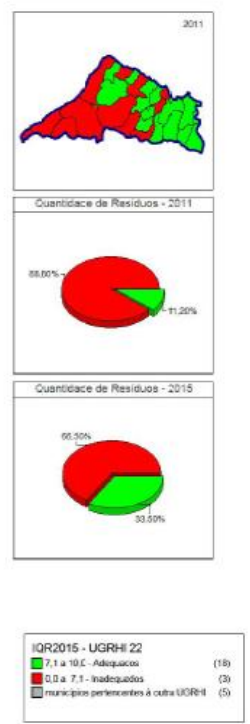

Fonte: Inventario Cetesb, 2015.

No que concerne às políticas públicas adotadas para a melhoria de gestão de resíduos sólidos, bem como, para o auxílio e o assessoramento dos municípios (CETESB, 2015), destacam-se:

- O Projeto Ambiental Estratégico LIXO MíNIMO ${ }^{4}$, objetivando eliminar a disposição inadequada de resíduos domiciliares no Estado de São Paulo, extinguir os lixões a céu aberto; aprimorar a gestão de resíduos domiciliares; e, fomentar a reciclagem e a minimização da geração de resíduos. Foram efetuadas inúmeras inspeções técnicas e aplicadas sanções corretivas, além da promoção de vários cursos e seminários de capacitação técnica a gestores de resíduos em municípios, atribuindo-se às ações do Projeto Ambiental Estratégico LIXO MíNIMO, os resultados substanciais alcançados no período de 2007 - 2011. O desenvolvimento e a implantação deste projeto visavam a aumentar a eficácia das ações de Governo quanto à gestão de resíduos no Estado e se alinhava com as ações empreendidas no Projeto VERDEAZUL.

- Programa MUNICÍPIO VERDE AZUL, objetiva estimular a participação dos municípios na política ambiental, com adesão ao Protocolo Verde Azul, além de certificar os municípios ambientalmente corretos, dando prioridade no acesso aos recursos públicos. Dentre as diretivas ambientais que devem ser atendidas pelos municípios, destaca-se a dos resíduos sólidos que privilegia as cidades cujo local de disposição recebe a classificação de IQR Adequado, bem como, as que possuem Plano Municipal de Gestão Integrada de Resíduos Sólidos, programa e/ou ações de coleta seletiva e ações de responsabilidade pós-consumo com setores produtivos para a coleta e destinação adequada de resíduos.

- Fundo Estadual de Recursos Hídricos - FEHIDRO, desde 1997, foram alocados recursos do FEHIDRO no montante de $R \$ 28,73$ milhões para a elaboração de projetos e a implantação de aterros sanitários, construção de centros de triagem e reciclagem de resíduos sólidos, elaboração de planos de gestão e gerenciamento integrado de resíduos sólidos, etc., por intermédio dos Comitês de Bacias Hidrográficas, observado o disposto na Lei 7.663, de 30 de

\footnotetext{
${ }^{4}$ Instituído pelas Resoluções SMA 21, de 16 de maio de 2007 e SMA 50, de 11 de novembro de 2007
} 
dezembro de 1991, e no Decreto 48.896, de 26 de agosto de 2004. A CETESB desempenha o papel de agente técnico do FEHIDRO, efetuando a análise de projetos e o acompanhamento de obras, com vistas à liberação dos recursos correspondentes.

- Programa de Aterros Sanitários em Valas ${ }^{5}$, foram celebrados 203 convênios, com os municípios que manifestaram interesse. Até 2008, os repasses do Estado alcançaram cerca de R\$ 2,0 milhões. Não estão sendo firmados novos convênios.

- Fundo Estadual de Prevenção e Controle da Poluição - FECOP ${ }^{6}$, até 2015, o Governo do Estado liberou $\mathrm{R} \$ 283,22$ milhões a 612 municípios para a aquisição de caminhões coletores $\mathrm{e}$ compactadores de lixo, caminhões para coleta seletiva, retro escavadeiras e pás carregadeiras, trituradores de galhos, tratores de esteira, centro de triagem de resíduos sólidos urbanos e da construção civil, implantação de ecopontos, etc., nos termos do Fundo Estadual de Prevenção e Controle da Poluição - FECOP;

- Programa Estadual de Implementação de Projetos de Resíduos Sólidos ${ }^{7}$, institucionaliza a atuação da Secretaria do Meio Ambiente no tema e cria uma estrutura de quatro projetos: (1) elaboração do Plano Estadual de Resíduos Sólidos, (2) apoio aos planos Municipais de Resíduos Sólidos, (3) melhoria na gestão dos resíduos, que se subdivide em responsabilidade pós-consumo, sistema declaratório, melhoria da gestão dos resíduos de construção civil, (4) educação ambiental para resíduos sólidos. O Programa contempla, também, estímulos à reciclagem, inclusive por meio de incentivos tributários e/ou fiscais; apoio à coleta seletiva, principalmente mediante a inserção social dos catadores; fiscalização, recuperação ou encerramento de atividades de destinação final de resíduos em situação inadequada e outras ações de uso racional dos materiais e redução na extração de recursos naturais. Conforme o Decreto acima, o Plano Estadual de Resíduos Sólidos foi concluído e divulgado em outubro de 2014 com as diretrizes/metas e ações para os próximos 10 anos. 0 apoio aos municípios se deu através de capacitação especifica (Gestão Integrada de Resíduos Municipais - GIREM) com material didático para elaboração dos seus planos em 2012, 2013 e 2014. Foram assinados 13 Termos de Compromisso com entidades (sindicatos e associações) ou diretamente com empresas, visando ao acompanhamento de sistemas de logística reversa no Estado. Foi desenvolvido junto com o setor da construção civil o Sistema de Gerenciamento On-line de Resíduos - SIGOR, que encontra-se em fase de implementação. Foi implantado conjuntamente com o movimento nacional dos catadores o Cadastro de Entidades de Catadores de Materiais Recicláveis do Estado de São Paulo - CADEC. Existem ações contínuas visando à adequação da destinação final dos resíduos por meio da fiscalização, orientação técnica e liberação de recursos para os municípios.

- Plano Plurianual - PPA ${ }^{8}$, onde são definidas as diretrizes, os objetivos estratégicos de Governo, as políticas públicas e os programas a serem executados em todo Estado, com metas para cada área de atuação: educação, saúde, saneamento, habitação, transportes, energia, entre outras.

Por meio de seus programas, a lei do PPA vincula as prioridades de Governo às demais leis orçamentárias: Lei de Diretrizes Orçamentárias - LDO e Lei Orçamentária Anual - LOA. Entre as metas estabelecidas existe um referente ao percentual de habitantes atendidos por

\footnotetext{
5 Estabelecido pelos Decretos 44.760, de 13 de março de 2000, e 45.001, de 27 de junho de 2000, permitindo a celebração de convênios entre a Secretaria do Meio Ambiente - SMA e 281 municípios de pequeno porte, com população de até 25.000 habitantes 6 Criado pela Lei 11.160, de 18 de junho de 2002.

${ }^{7}$ Criado em fevereiro de 2012, por meio do Decreto Estadual n ${ }^{\circ}$ 57.817/2012 foi instituído o Programa Estadual de Implementação de Projetos de Resíduos Sólidos

${ }^{8}$ A Lei n ${ }^{\circ} 16.082$, de 28 de Dezembro de 2015, institui o Plano Plurianual - PPA para o quadriênio 2016-2019.
} 
aterros de resíduos urbanos com disposição adequada (\%), com base no Inventário Estadual de Resíduos Sólidos Urbanos.

- Índice de Efetividade da Gestão Municipal, o Tribunal de Contas do Estado de São Paulo possui um processo de apuração de indicadores finalísticos destinados a compor o Índice de Efetividade da Gestão Municipal, instrumento que se dispõe a evidenciar a correspondência das ações dos governos às exigências das comunidades, inicialmente em sete especialidades, sendo uma delas a ambiental. É apresentada uma lista com o posicionamento de municípios jurisdicionados com indicadores que estabelecem uma métrica das ações sobre o meio ambiente que impactam a qualidade dos serviços e a vida das pessoas, como exemplo: resíduos sólidos, educação ambiental, estrutura ambiental, conselho ambiental etc. Para a elaboração do Índice é fornecida a cada órgão jurisdicionado uma série de quesitos específicos de meio ambiente que devem ser respondidos eletronicamente pelo Sistema Audesp. O IQR elaborado pela CETESB é utilizado para o entendimento dos processos quanto à qualidade dos resíduos sólidos, cujo manejo é de responsabilidade municipal.

- Programa Otimização da Gestão Municipal de Resíduos Sólidos no Estado de São Paulo, das Diretrizes 2015-2018, uma das 5 (cinco) diretrizes estabelecidas pelo Sistema Ambiental Paulista, que representam as principais linhas de atuação da política ambiental do Estado de São Paulo, é a diretriz que visa aprimorar a gestão de resíduos sólidos, com foco não só na reciclagem e na disposição final, mas englobando também a produção e o consumo sustentáveis, de modo a atender às Políticas Nacional e Estadual de Resíduos Sólidos. Alguns dos programas inseridos nesta diretriz são: Otimização da Gestão Municipal de Resíduos Sólidos no Estado de São Paulo cujo objetivo é apoiar a gestão e o gerenciamento de resíduos nos municípios do estado e fiscalizar os locais de destinação de resíduos nos municípios; Programa Estadual de Logística Reversa com o objetivo de implementar sistemas de logística reversa, com conteúdo padronizado, para os produtos listados em Resolução; Programa Estadual de Monitoramento da Gestão de Resíduos Sólidos para implementar o Sistema Estadual de Gerenciamento On-Line de Resíduos Sólidos (SIGOR) no território do Estado e definir e publicar indicadores para monitorar a implementação do Plano Estadual de Resíduos Sólidos; e o Programa Estadual de Educação Ambiental para a Gestão de Resíduos Sólidos com o objetivo de promover ações de articulação institucional e realização de consultas públicas para elaboração do Programa Estadual de Educação Ambiental para Resíduos Sólidos.

\section{RESULTADOS E DISCUSSÕES}

O lixão é conhecido como aterro controlado, um lixão que foi melhorado, mas são incompatíveis com a proteção ambiental, por não haver monitoramento constante e não existe critérios para disposição de resíduos.

Conforme a CETESB (2016), o município que possuir lixo acima de 10 toneladas por dia deve obrigatoriamente dispensar os lixos em aterros sanitários adequados, ou seja um terreno que tenha a impermeabilização do solo, que possua tratamento especializado e monitoramento evitando assim a poluição e utilizando os gases tóxicos para geração de fonte de energia. Logo o munícipio de Presidente Prudente gera mais de 10 toneladas/dia, devendo obrigatoriamente possuir um aterro sanitário. Foi construído 5 poços para realizar o monitoramento na área do lixão para realizar o passivo e a análise do solo e da água, já que em sua proximidade existe uma nascente. 



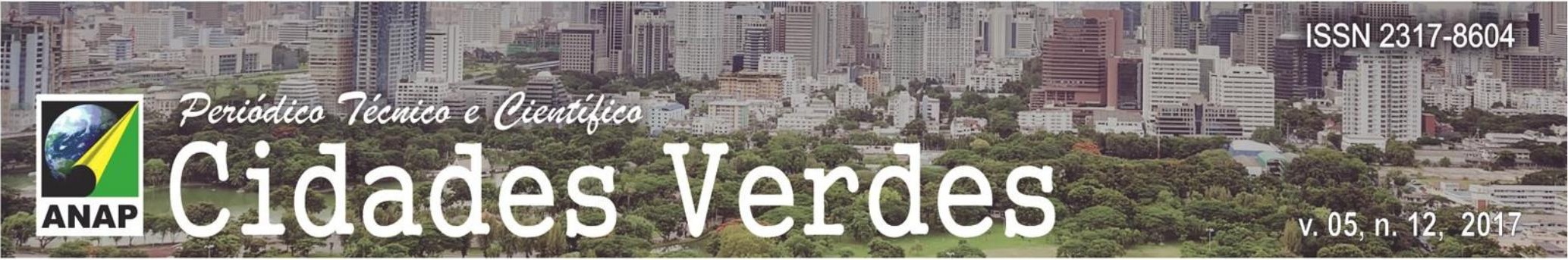

BRASIL. Lei no 14.676, de 28 dezembro de 2011. Institui o Plano Plurianual para o quadriênio 2012-2015. São Paulo: 28 Disponível em: http://www.planejamento.sp.gov.br/noti anexo/files/planejamento orcamento/ppa/PPA201 22015/Lei 14676.pdf Acesso em: 10 nov. 2016.

CETESB - COMPANHIA AMBIENTAL DO ESTADO DE SÃO PAULO. Inventário Estadual de Resíduos Sólidos Urbanos 2015. São Paulo: CETESB, 2016.

GOVERNO DO ESTADO DE SÃO PAULO. CETESB. Panorama dos Resíduos Sólidos do Estado de São Paulo. Versão Preliminar. São Paulo: CETESB, 2014.

IBGE. Normas de apresentação tabular. 3. ed. 1993.

LAKATOS, Eva Maria; MARCONI, Marina de Andrade. Fundamentos de metodologia científica. 3. ed. rev. e ampl. São Paulo: Atlas, 1991. 270 p.

RAMOS, S. P. A Lei da Política Nacional de Resíduos Sólidos e a meta de implantação de aterros sanitários no Brasil. In: Âmbito Jurídico, Rio Grande, XVII, n. 121, fev 2014. Disponível em: $<$ http://ambitojuridico.com.br/site/?n_link=revista_artigos_leitura\&artigo_id=14280\&revista_caderno $=5$ >. Acesso em: 02 dez 2016.

TAKENAKA, E. M. M. Políticas públicas de gerenciamento integrado de resíduos sólidos urbanos no município de Presidente Prudente - SP. Presidente Prudente: [s.n.] 2008. Disponível em: http://repositorio.unesp.br/bitstream/handle/11449/105028/takenaka emm dr prud.pdf> Acesso em: 20 nov. 2016. 